\title{
PRESENT STATUS AND FUTURE PROSPECTS OF AUTOMATED PROJ ECT PERFORMANCE INDICATORS' MEASUREMENT
}

\author{
Ronie Navon \\ Faculty of Civil \& Environmental Engineering \\ Technion City, 32000 Haifa, Israel. \\ E-mail: ronie@technion.ac.il
}

\begin{abstract}
Current monitoring and controlmethods rely on massive manual work. As a result, control information is expensive to acquire, or is generated irregularly. Additionally, the information is only available infrequently and its quality and integrity are low. The purpose of the work presented in this paper is to improve monitoring and control information, i.e. to offer it on a daily basis, to improve its quality and integrity and to reduce the cost of generating it. To do all this, the Technion APPC researcher group started exploring the use of automated data collection (ADC) technologies. We developed models for automated labor and earthmoving equipment control, as well as models which utilize data from an existing systems - daily site reporting and building programs.
\end{abstract}

Keywords: Automation; Data collection; Feedback control; Control methods; Monitoring

\section{INTRODUCTION}

Industrial managers find continuous, real-time and detailed, performance measurement, an indispensable tool, thus permitting corrective measures to be taken while the work is still in progress. Taking into account that the rate of rework in construction exceeds $10 \%$ and the waste of resources (especially labor) surpasses $20 \%$ [1-5], such tools are needed in the construction industry too. Manual measurement is labor intensive ${ }^{1}$, is error prone and is inefficient in an industry where a typical activity takes days, while measuring the actual performance and analyzing it normally takes weeks.

This paper describes some of the major Automated Project Performance Control research in the areas of (1) productivity and progress measurement - in two areas: labor control and the control of earthmoving operations in road construction, (2) models developed to utilize data from existing systems - daily site reporting and building programs.

\section{PRODUCTIVITY \& PROGRESS MEASUREMENT}

Productivity and progress are two very important project performance indicators (PPI). As there is no direct method to automatically measure them, our research proposes to measure indirect parameters and convert them into productivity, or progress measures. This indirect parameter in our research is the location of the construction agent - worker or equipment.

The basic concept behind the selection of the indirect parameter is the fact that to construct a building element the worker, or the equipment, has to be close to it (within arm's reach). Therefore, knowing the worker, or equipment's location at a given time, together with additional information, the activity s/he/it is performing can be determined. The time

\footnotetext{
${ }^{1}$ In some cases up to $50 \%$ of field supervis ory pers onnel time is spent recording and analyzing field data.
}

and the worker, or equipment's location are measured automatically using automated data collection (ADC) technology.

\subsection{Labor Tracking}

\subsubsection{Model and Field Experiments}

A preliminary model that converts workers' locations into labor productivity and progress was developed [6, 7]. The model uses two sources of data: (i) the Project Model (PM), which provides data referring to the planned inputs, the schedule and the physical design of the building itself; and (ii) data relating to the actual performance, as measured by the ADC module, which uses ADC technology to measure the location of each worker at regular time intervals. The model uses these locations to convert them into actual productivity, to compare the latter to the planned ones, to determine the progress and produce the output.

The model calculates the time workers spend being involved with each activity and as sociates it with the amount of work performed by the worker, or the crew, using the work envelope (WE) concept. A WE describes a volume in space, within the proximity of the building element to be installed, in which it is assumed that a worker must be physically present in order to perform a construction activity on that element. After determining the Pending Activities ${ }^{2}$ (PA) the model determines specific WE for each PA. By associating the locations, measured by the ADC Module, to WE (each related to a different PA), the model links the times the workers spent in a WEto an activity. The as sociation is done using different sets of decision rules (DR). Based on the location to activity association, the model calculates the duration of time workers spend performing each activity. After determining the completed activities, the model

\footnotetext{
${ }^{2}$ All the activities whose predecess ors are completed, which means that they can be performed on the given day.
} 
calculates the actual productivity, compares them to the planned ones and generates the output, including progress.

Field experiments were conducted in three construction sites, which included a location manual measurement and simultaneous conventional measurement of the same activities. The manual location measurement simulated the ADC by "measuring" relative locations at regular time intervals. These locations were converted into inputs/productivity by the model and compared to the results of the conventional measurements.

Twelve activities were monitored in one of the sites in ten of them the difference between the time measured manually and that calculated by the model was less than \pm $12 \%$. In the other two activities the deviation was up to \pm $22 \%$. The experiment was conducted with different sets of DR. It is important to emphasize that in all the activities where the deviations exceeded $\pm 10 \%$ using one set of DR, the deviation using the other was meaningfully smaller. More details about the model, the site experiments and the project model can be found in Navon and Goldschmidt [7].

\subsubsection{Determination of the Experimentation Tool}

The current stage of the research attempts to answer two questions: (i) what are the expected accuracies of the model? And (ii) what factors affect these accuracies? Extensive site experiments have to be conducted to answer these questions. In these experiments the locations of workers will have to be measured continuously. Because suitable off-the-shelf ADC technologies are not yet available, the previous stage of the research was based on manually simulated location measurement [7]. In search of a suitable tool for the field experiments, a test using geodetic GPS technology was conducted in frame-construction activities, as suming that a building frame is a relatively open environment, whereby the GPS receiver can maintain a clear line-of-sight with the satellites. Worker locations were measured by the GPS and in parallel the actual work was monitored manually. The result of this test was that $53 \%$ of the locations were correctly associated by the model - this result was worse than the results in the previous stage using simulated location measurement.

To determine whether the discrepancy between the resulting measurement accuracy stems fromthe suitability of the measurement tool, tests are currently conducted using a continuous video photography. The video will be analyzed manually, in two stages, by downloading single frames at regular time difference (e.g. one minute); measuring the location of the workers using a special grid; and, in a different session analyzing manually the actual work. The advantage of this method compared to the GPS is that both the location measurement and the determination of the actual work are based on the same source and that they can both be done objectively and verified at any stage. The results of these experiments will be reported in Tokyo.

\subsection{Earthmoving Operations Control}

\subsubsection{Model and Field Experiments}

The principles used for labor tracking served as the basis for the Earthmoving Operations model, which was implemented in a prototype system for controlling road construction operations [8]. The model compares between the planned and the actual values of progress and productivity variables. This model, too, has two main sources of data: (i) The Project Model (PM), containing the planned schedule, the planned productivity, and all the data regarding the physical design of the road. And (ii) the Location Measurement Module (LMM), using GPS. This module measures the location of each member of the fleet at regular time intervals. The module records the time of measurement, the identification of the equipment and its location.

The model begins the process by extracting all the pending activities, the geometrical values of the road, the planned quantities of work and the planned productivity. Specific Work Envelopes (WE) are calculated for each pending activity. The WEs correspond with planned work sections, as represented in the schedule. Next, a geometrical calculation as sociates each of the locations to these specific WEs, by checking if the measured location is included within the WE. This enables the model to determine which activities are actually being performed. Once the modelidentifies that a new activity has started, it also determines which of the activities are completed. The cycle ends by determining the actual time spent performing each activity, and the productivity, which is based on this time and the quantities.

The output of the model compares the actual performance, as measured and calculated by the model, to the planned one. It includes: (i) a comparison between the actual productivity and the planned one, extracted by the PM Interface. And (ii) a comparis on between the actual progress and the planned one according to the updated schedule, also extracted by the PM Interface.

This model was realized in a prototype system and tested in the field for three weeks on a road construction site, using GPS mounted on each of the pieces of equipment performing the controlled activities. The productivity of four activities was measured with the prototype system and, at the same time, it was recorded manually so that the accuracy of the model could be assessed. The comparison showed that the deviation between the actual productivity and the one calculated by the prototype was $-2.2 \%$ to $+4.4 \%$. These results are encouraging, indicating that automated productivity measurement of earthmoving equipment in road construction is possible. Moreover, the measurement technology (GPS) is available off-the-shelf and affordable. 


\subsubsection{Dynamic Work Envelopes}

The model applied the principles of the labor tracking model (Section 2.1), namely that the road is divided into predefined work sections (WS). While this assumption is logical in building construction ${ }^{3}$, it is often not the case in road construction. We discovered during the field tests that at the end of each working day we had to manually define the WS. This lead to the current stage, whereby a new concept for WE and WS is being considered.

Instead of associating locations to activities in a two stage association procedure - as explained in Navon and Shpatnitsky [8] - by predetermining WSs and corres pondingly WEs, the algorithm will determine the WEs dynamically during its operation, according to the measured locations. Various algorithms were considered for the dynamic work envelope (DWE) algorithm. The first is called Minimum ConvexPolygon (MCP). This algorithmdetermines the area of the minimal convex polygon which encompasses all the measured locations. The advantage of this algorithmis its simplicity. The problem with it, on the other hand, is that the calculated area includes the entire area encompassing all the measured locations [9], which means that even areas where work was not performed, are included. The second algorithm is called Kernel Density Estimation (KDE) algorithm, which is more sophisticated - it is based on statistical principles and hence is more accurate [10]. This algorithm is capable of identifying and subtracting areas where there is no concentration of locations and is also capable of ignoring incidental readings.

An initial field test of the two algorithms was conducted. A GPS receiver was installed on a car, which simulated the work of a compactor by driving slowly forwards and backwards covering a section of a road to be compacted. During this drive the GPS recorded the measured locations of the car. Back in the lab, these locations were fed into the two algorithms, which calculated the areas represented by these locations.

The results of this experiment indicate that these algorithms are capable of determining the area represented by the measured locations; hence they are suitable to serve as part of the DWEalgorithm. As for their accuracy, the areas calculated by the two algorithms were compared to a manual calculation of the area covered by the simulated compaction. The latter area is $42 \mathrm{~m}^{2}$, while the area calculated by the MCP is $108 \mathrm{~m}^{2}$ and the one calculated by the KDE is $61 \mathrm{~m}^{2}$.

The next step of this research will look into ways of changing the KDE algorithm to improve its accuracy. Once this is done, more field experiments will be conducted, this time with various types of earthmoving equipment in an ongoing road construction project. The results of these experiments will be reported in Tokyo.

\footnotetext{
${ }^{3}$ E.g. a slab, or a wall, are well defined hence they can serve as a good basis for WS determination
}

\section{TRADITIONAL-TOOLS BASED MONITORING}

The ideas in Section 2 are based on ADC to collect monitoring data. The present Section explores the possibilities to use data from traditional tools for automated monitoring. This approach is applied using daily site traditional reporting and a building program.

\subsection{Daily-Site-Reporting Based Monitoring}

The daily site report (DSR) is one of the most important records during construction [11]. The DSR normally holds a vast amount of data, such as [11-13]: number of workers broken down to trades; materials arriving to the site; number and type of equipment; receipt of drawings and plans; weather conditions; contractors, or subcontractors; work accomplished; major events; problems; etc. - all these data are logged on a daily basis, which means that they are very detailed and up-to-date. Unfortunately, such a valuable source of reliable and detailed data is not normally used for management and control of the ongoing project - it is mainly used for litigation: claims and disputes [11, 12] - and sometimes for billing purposes.

A computerized DSR will serve as a data collection tool to build a database which contains data regarding the actual performance of the project [13]. These data, which are collected anyhow for other purposes, will be processed, by algorithms developed for this purpose, to generate managerial information regarding the actual events occurring in the project. This information will be used to control the project in real-time on a daily basis and generate warnings when deviations occur. Additionally, because the database includes variables such as the number of workers for each trade, the materials arriving to the site, the us er will be able to easily analyze the reasons for the deviation and, thus, be much more informed to take corrective measures.

\subsubsection{Model}

The model uses data from two sources: the schedule and the computerized DSR. The schedule includes data regarding all the project's activities, the relationships between them, their code and description, their durations, their start/finish information and the floats.

When filling the computerized DSR, the user enters, among others, data for all the ongoing activities. The user selects the activities, for the given day and for each, s/he enters the work section (selected from a pre-defined list), percent complete, manpower employed for the performance of the activity, and the number of hours worked on the activity during the given day. The latter two are used for labor monitoring.

The model is also designed to compare the planned with the actualperformances and issue warnings when there are deviations which exceed a predefined value - the project management team can then analyze the causes for these deviations and take corrective measures. Additionally, the data collected with the DSR can be proces sed and stored in a 
Historical Database, which can be used for future planning and control purposes.

\subsubsection{Implementation}

The current implementation refers to the part of the computerized DSR which supports the progress monitoring. The concept proving prototype uses Excel for the daily data entry into the DSR, as well as its processing using Visual Basic for Applications (VBA). MS Project is used for the planned and the as made schedules. The data transfer between MS Project and Excel is done automatically and the way back - fromExcel to MS Project, to update the As Made Schedule - is done by importing an Excel data file into MS Project.

The use of the prototype will be demonstrated with a case study, synthetic, project comprised of three activities: $\mathrm{A}, \mathrm{B}$ and $\mathrm{C}$. The scheduled durations of these activities are 10, 12 and 8 days correspondingly. The relationships between the activities are finish-start. The resulting planned schedule, in a Gantt Chart format, is represented in Figure 1 by the upperbar of each activity. After collecting data for 28 days and updating the schedule ${ }^{4}$, the status of the project can be analyzed.

Activity A started on time and was completed early, after seven working days instead of 10. Consequently, activity B started three days earlier. Activity B was, all the same, completed four days later than scheduled, the reason for which is that the work was not done continuously. Moreover, Figure 1 shows that the work on activity B took fourteen cumulative days, instead of the twelve scheduled days. Activity $\mathrm{C}$ started four days later than scheduled due to the late completion of activity $\mathrm{B}$, but is progressing faster than scheduled. The latter conclusion is made based on the fact that although only two days passed from the start of the actual work, which is $25 \%$ of the time allocated for this practice, a lot of data would have to be collected manually, which is labor intensive and expensive. Additionally, as opposed to the accurate and reliable nature of the data extracted from the DSR, the manual data collection is error prone.

We are planning to develop more monitoring and control tools which will use data from the computerized DSR. These plans include (a) enhancing the capability of the DSR tool to is sue warnings when the actual performance deviates from the planned one; (b) updating the Historical Database to enable better future planning; (c) monitoring and control of various resources, such as labor and materials; and (d) generation of various lists such as current, or completed, activities for a given time horizon.

\subsection{Building-Program Based Monitoring}

Change orders are seen as a major cause of project delay and a source of many disputes [14]. The primary causes of change orders are owner-initiated changes and designer's errors and omissions $[15,16]$. In order to achieve client satisfaction and improve project performance, a change management procedure should be established that includes the consideration of potential value and associated risk of a proposed change [17]. Another research points out, however, that due to the usually large number of changes during the design process, the project teamhas to make rapid decisions on how to solve a specific issue, and it is often difficult to notice all interdependencies between project requirements [18]. Kiviniemi et al. conclude that changes of requirements are not well documented because the design tools do not support such documentation, and decisions are based on previous design solutions, instead of the requirements.

Successful change management should include an

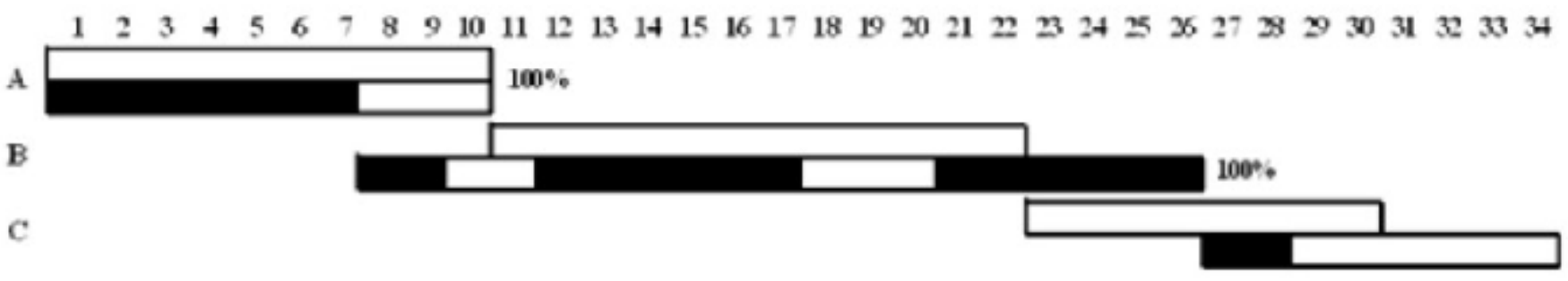

Figure 1: Case study project

activity, $50 \%$ of the work on this activity was completed.

\subsubsection{Conclusions and Future Plans}

The prototype and the case study project demonstrate the potential of such a tool for real-time progress monitoring. In order to performa detailed and accurate analys is in current

\footnotetext{
${ }^{4}$ The lower bar of each activity represents the actual work and the percent complete is marked on the right side of the bars.
}

assessment of the impact of a proposed change, which is meeting one requirement, on all other requirements. However, traditional paper-based methods fail to support critical group decision-making tasks because they do not communicate relationships between project information [19].

A Change Management Tool (CMT) is being developed to support the group decision process in which change proposals for construction projects are evaluated. The CMT will be based on improving requirements information management. 


\subsubsection{Principles of the Proposed Solution}

The CMT is a decision support system that aids the process in which change proposals are evaluated by managing and manipulating the project information. The building program serves as a framework for the CMT, with links to the client requirements and the building design. These three sources of information in the project can also be seen as different models of information, each based on a different abstraction of the project. The structure of these models in the CMT makes it possible to link specific data:

- The Client Requirements are analyzed using an activity-based approach [20]. The client's functional environment is divided into specific activities that realize the client's goals, and are therefore value-adding (e.g. Teaching, Research, Administrative activities). This ensures that the requirements are systematically mapped and are defined in a structured form.

- The Building Program divides the planned project into spaces, and presents the requirements for each space. The requirements for a space are defined according to attributes of the activities taking place within that space, together with other sources such as building codes and the project team knowledge.

- The Building Design divides the project into discrete building systems: structure, plumbing, HVAC, electrical, etc. Each system consists of a large number of components designed to connect in a particular way. Each system is designed to meet a different set of requirements, and a built component is designed according to the attributes, specified in the building program, of the space in which it is located.

The CMT is designed to identify the scope of the impact of a proposed change, using requirements traceability capabilities. This is done on two levels: on the level of a specific space, and on the level of the entire project.

\subsubsection{Conclusions and Future Plans}

The objective of this research project is to assess the feasibility of a CMT that supports the decision process in which change proposals are evaluated by identifying their implications.

A prototype of the CMT, based on Microsoft Excel, has been implemented to examine the ability of the proposed tool to identify the implications of a proposed change, and support the decision process in which this change is evaluated. Using this tool, a pilot study has been conducted of a project in which several changes had been introduced. The project involved the expansion of a maternity ward in a hospital, and the changes which were made in the project brought an increase in costs which eventually led to its suspension.

The pilot study, conducted using a prototype tool, has given positive results. The CMT might have prevented the extensive delay and additional design-costs in this project, by identifying the impact of the proposed changes at the moment they were raised. It could also have indicated the need for an adjustment in the scope of the project, and facilitated the investigation of various trade-offs, before the design was finalized. It remains however, to further develop and test this tool in order to reach a final conclusion.

\section{CONCLUDING REMARKS}

Automated PPI measurement, monitoring and control is a relatively new and growing area. Modern construction management requires up-to-date, relevant, and accurate feedback information from the site regarding the actual performance of the project - this information is often unavailable, or requires massive manual work. Even when available, this information reflects events occurring, or even completed, long time before. This unfulfilled need, together with the prospects offered by the rapid improvements in $\mathrm{ADC}$ technology, is the major driving force behind the developments in automated PPI measurement.

\section{ACKNOWLEDGMENTS}

This research was partly supported by THE ISRAEL SCIENCEFOUNDATION (grant No. 444/05). This support is gratefully acknowledged. I would like to thank my colleagues for their invaluable contributions to the research projects described in this paper. They are M. Abdelsayed, Y. Doytsher, E. Goldschmidt, I. Haskaya, S. Isaac, S. Khoury, and Y. Shpatnitsky.

\section{REFERENCES}

1. Love, P.E.D., et al., M odeling the dynamics of design error induced rework in construction projects. Construction Management and Economics, 2000. 18(5): p. 567-574.

2. McKim, R., T. Hegazy, and A. Attalla, Project Performance Control in Reconstruction Projects. Journal of Construction Engineering and Management, ASCE, 2000. 126(2): p. 137-141.

3. Chrysostomou, V., CALIBRE - the UK's Construction Industry Added Value Toolkit, in International $C$ onference on the U se of Automatic Data Collection in Construction. 2000: Las Vegas, Nevada, USA.

4. Han, S.W., S.Y.Lee, and D.W. Halpin. Productivity Evaluation of Conventional and GPS-Based Earthmoving Systems Using Construction Simulation. in Construction Research Congress. 2005. San Diego, USA: ASCE.

5. McCullouch, B. Automating Field Data Collection in Construction Organizations. in Construction Congress V, ASCE. 1997. Reston, VA.

6. Goldschmidt, E. and R. Navon. Automated Real-Time M an power Productivity Control. in The Eighth International Symposium on Organization $\&$ M anagement of Construction. 1996. Glasgow, UK.

7. Navon, R. and E. Goldschmidt, C an Labor Inputs be Measured and Controlled Automatically? Journal 
of Construction Engineering and Management, ASCE, 2003. 129(4): p. 437-445.

8. Navon, R. and Y. Shpatnitsky, Field Experiments in Automated M onitoring of Road Construction. Journal of Construction Engineering and Management, ASCE, 2005. 131(4): p. 487-493.

9. Seaman, D.E., et al., E ffects of Sample Size on Kernel Home Range Estimates. Journal of Wildlife Management, 1999. 63(2): p. 739-747.

10. Silverman, B.W., Density Estimation for Statistics and Data Analysis. 1986, London, UK: Chapman and Hall.

11. Liu, L.Y., et al. Construction Daily Log $M$ anagement System U sing M ulti M edia Technology. in Second Computing in Civil Engineering Congress. 1995. Atlanta, USA: ASCE.

12. Russell, A.D., Computerized Daily Site Reporting. Journal of Construction Engineering and Management, ASCE, 1993. 119(2): p. 385-402.

13. Abdelsayed, M. and R. Navon, An Information Sharing, Internet-Based, System for Project Control. Civil Engineering and Environmental Systems, 1999. 16(3): p. 211-233.

14. Lo, T.Y., I.W.H. Fung, and K.C.F. Tung, Construction Delays in Hong Kong Civil Engineering Projects. Journal of Construction Engineering and Management, ASCE, 2006. 132(6): p. 636-649.

15. Manavazhi, M.R. and Z. Xunzhi, Productivity oriented analysis of design revisions. Construction Management and Economics, 2001. 19(4): p. 379-391.

16. Love, P.E.D. and H. Li, Quantifying the causes and costs of rework in construction. Construction Management and Economics, 2000. 18(4): p. 479-490.

17. Othman, A.A.E., T.M. Hassan, and C.L. Pasquire, Drivers for dynamic brief development in construction. Engineering, Construction and Architectural Management, 2004. 11(4): p. 248-258.

18. Kiviniemi, A., et al., Premiss - Requirements Management Interface to Building Product Models: Problem Definition and Research Issues, in CIF E Working Paper. 2004, Stanford University.

19. Liston, K., J. Kunz, and M. Fischer. Requirements and Benefits of Interactive Information Workspaces in Construction. in The 8th International Conference on Computing in Civil and Building Engineering. 2000. Stanford, USA.

20. Pennanen, A., M. Whelton, and G. Ballard, Managing stakeholder expectations in facility management using workplace planning and commitment making techniques. Facilities, 2005. 23(13/14): p. 542-557. 